\title{
SOBRE O FINANCIAMENTO NO PLANO DE DESENVOLVIMENTO DA EDUCAÇÃO
}

\author{
RUBENS BARBOSA DE CAMARGO \\ Faculdade de Educação da Universidade de São Paulo \\ rubensbc@usp.br
}

\section{JOSÉ MARCELINO DE REZENDE PINTO}

Faculdade de Filosofia, Ciências e Letras da Universidade de São Paulo - Ribeirão Preto jmrpinto@ffclrp.usp.br

\section{JOSÉ LUIZ GUIMARÃES}

Faculdade de Ciências e Letras da Universidade Estadual Paulista - Assis

jluiz@assis.unesp.br

\section{RESUMO}

Este artigo apresenta uma análise inicial do financiamento das ações do Plano de Desenvolvimento da Educação - PDE -, lançado em abril de 2007 pelo governo federal, focalizando algumas expectativas, impasses e impactos. Muitas das inquietações e dúvidas aqui expostas foram manifestadas no Seminário Itinerante O Plano de Desenvolvimento da Educação - PDE - em Debate nas Universidades Públicas Paulistas, em que especialistas de diferentes instituições tiveram a oportunidade de debater com os formuladores e responsáveis pela implementação do plano. Optou-se por organizar análise em três partes. Na primeira parte, discutem-se alguns pressupostos do financiamento da educação nacional, mostrando que o país pode e deve aplicar mais recursos para alcançar um desenvolvimento educacional e social adequado. Na segunda, analisam-se documentos do MEC que explicitam as concepções que fundamentam o PDE no que se refere ao financiamento das 40 ações propostas. Na terceira, os autores se posicionam quanto à forma de financiamento adotada e quanto aos recursos previstos ou alocados para a execução das ações. Para finalizar, uma série de questões sobre o plano são levantadas em perspectiva propositiva.

POLITICAS EDUCACIONAIS - FINANCIAMENTOS DA EDUCAÇÃO - PLANO DE DESENVOLVIMENTO DA EDUCAÇÃO

\section{ABSTRACT}

THE EDUCATION DEVELOPMENT PLAN: MATTERS ON FUNDING. This article presents a preliminary analysis of PDE (Education Development Plan) that was launched by the Brazilian federal government in April 2007, in order to address some expectations, impasses, and impacts. Much of the uneasiness and doubts we approach arose in the itinerant seminar "The Education Development Plan - PED - under Discussion in São Paulo Public Universities", in which specialists 
from different institutions had the opportunity to debate the plan with those who were responsible for creating and implementing the plan. We have organized the analysis in three parts. In the first part, we discuss some presuppositions of national education funding and show that Brazil can and should invest more resources in order to attain adequate social and educational development. In the second part, we analyze documents of the Ministry of Education evidencing the conceptions on which the PDE is based with regard to funding of the 40 proposed actions. In the third part, the authors take a position on the form of funding adopted and the resources foreseen or allocated to carry out actions. Finally, a series of issues concerning the plan are raised from a propositional perspective.

EDUCATIONAL POLICIES - EDUCATIONAL FINANCE - EDUCATION DEVELOPMENT PLAN

Neste artigo pretende-se analisar a proposta de financiamento do Plano de Desenvolvimento da Educação - PDE -, lançado em 2007 pelo Ministério da Educação, focalizando as expectativas, os impasses e os impactos por ele gerados.

Sem pretender alcançar todas as dimensões que envolvem a análise do financiamento do PDE, optamos por organizar o trabalho em três partes: a. pressupostos do financiamento da educação nacional; b. percepções de questões relativas ao financiamento do PDE; e c. posicionamentos sobre o financiamento do PDE. Na primeira parte, apresentamos alguns argumentos e pressupostos sobre a questão do financiamento da educação de modo amplo, e procuramos mostrar que o país pode e deve aplicar mais recursos no setor para alcançar um desenvolvimento social mais adequado, combatendo fragilidades e déficits educacionais nacionais, e que é possível superar as profundas desigualdades regionais. Na segunda parte, analisamos documentos do MEC que explicitam um pouco mais as concepções e as ações propostas no PDE, tentando perceber melhor alguns aspectos relativos ao seu financiamento. $\mathrm{Na}$ terceira parte, há um posicionamento dos autores quanto à forma de financiamento das $40^{\prime}$ ações propostas, pautado na construção de matriz com a descrição das ações e dos atos normativos que as fundamentam e dos recursos financeiros previstos, ou alocados, para a sua execução. Concluímos com alguns questionamentos numa perspectiva propositiva sobre o PDE.

I. Quando este artigo foi escrito este era o total de ações. Em julho de 2008, seu número já havia passado a 53, o que mostra o caráter pouco orgânico do PDE. 


\section{PRESSUPOSTOS DO FINANCIAMENTO DA EDUCAÇÃO NACIONAL}

Os déficits educacionais existentes no país são do conhecimento de todos. Há falta de vagas em creches e pré-escolas públicas. $\bigcirc$ ensino fundamental, embora com acesso quase universalizado, não garante a permanência dos alunos, com taxa esperada de conclusão de cerca de metade dos ingressantes e uma jornada de apenas 4 horas em escolas onde faltam bibliotecas e laboratórios de ciências e informática (menos de um quinto delas possuem esses equipamentos). Há mais de 60 milhões de pessoas acima de 15 anos não completaram o único nível de ensino obrigatório. $\bigcirc$ ensino médio, com matrículas em baixa, metade das quais oferecidas no período noturno, não aponta perspectiva de futuro para os jovens. $O$ ensino superior ainda atende uma pequena parcela da população de 18 a 24 anos, a minoria nas boas instituições do setor público, que admite apenas em cada dez estudantes que prestam o vestibular, e mais de $70 \%$ em faculdades privadas de qualidade duvidosa. Na educação inclusiva, destacam-se as formas limitadas de atendimento e a pequena oferta (quase sempre em convênio com instituições privadas sem fins lucrativos).

Completam o quadro a formação precária, os baixos salários, as doenças crônicas e a carência de professores em todos os níveis; a inexistência de processos participativos para definir os rumos das instituições educacionais; a carência de uma qualidade socialmente referenciada; o reduzido monitoramento do ensino oferecido pelo setor privado; a ausência de um sistema nacional de educação; e o limitado controle social sobre os recursos financeiros destinados legalmente à educação.

Passados dez anos de seu envio para discussão no Congresso Nacional, e sete anos de sua aprovação na forma de lei, o Plano Nacional de Educação - PNE - é sistematicamente ignorado pelo executivo federal e por seus congêneres estaduais e municipais.

Recorde-se que no período de 1998, ano de sua apresentação ao Congresso, a 200 I, quando a lei foi sancionada, houve um embate de projetos para a educação nacional. De um lado, o projeto de PNE apresentado pelo MEC; de outro, o Plano Nacional de Educação: Proposta da Sociedade Brasileira, elaborado no âmbito dos Congressos Nacionais de Educação - Coneds -, com análises, propostas e posições muito distintas.

Recorde-se também que o produto final do embate - a lei aprovada - 
previa mais recursos para a educação pública nacional. Entre seus dispositivos constava que deveriam ser aplicados 7\% do PIB no ensino público (a Unesco recomenda um mínimo de 6\%). Embora seu relator, o deputado Nelson Marchezan, pertencesse ao partido no poder, a lei sofreu nove vetos do então presidente Fernando Henrique Cardoso, quase todos envolvendo o aumento de recursos - vetos que o atual governo, em dois mandatos, não se esforçou em derrubar.

Nessas condições, não há como superar as condições acima descritas e diagnosticadas. Como afirma um documento recente do Grupo de Trabalho de Educação da Associação de Docentes da Universidade de São Paulo Adusp,

... nenhum país jamais conseguiu cruzar a barreira do atraso educacional, sem um aporte de recursos adequados. Países que superaram (ou estão superando) atraso escolar semelhante ao nosso aplicaram (ou estão aplicando) cerca de 10\% de seus PIB com a educação pública. Valores típicos encontrados nos países que mantêm um desempenho educacional razoável ou bom são da ordem ou superiores a 7\% do PIB. (GT Educação da Adusp, 2008, p.3)

Mas, como saltar dos atuais 4\% do PIB estimados pelo MEC, que, como sabemos, incluem uma série de artifícios contábeis feitos pela União, estados e municípios para inflacionar as despesas em educação, para 10\%? Ou mesmo, para os $7 \%$ previstos originalmente, no PNE? De onde viriam os recursos?

Em primeiro lugar, é imperativo acabar com o engodo midiático de que "os recursos existem, mas são mal administrados". Como mostram sistematicamente os relatórios das agências internacionais (Programa das Nações Unidas para o Desenvolvimento - PNUD -; Comissão Econômica para a América Latina e o Caribe - Cepal -, Organização para a Cooperação e Desenvolvimento Econômico - OCDE), os gastos por aluno na rede pública de educação básica no Brasil são cerca de $40 \%$ menores que aqueles praticados por países como Chile e Argentina e cerca de um quinto da média nos países ricos. Além disso, esses gastos representam cerca de um terço do valor das mensalidades cobradas nas escolas do país freqüentadas pela classe média.

Em segundo lugar, é necessário enfrentar concretamente questões relativas ao financiamento da educação dentro do contexto mais amplo das 
relações tributárias. Isso implica combater a sonegação, opor-se a medidas imediatistas, como anistia aos sonegadores e renúncias fiscais; exigir o fim da Desvinculação dos Recursos da União - DRU -, que retira 20\% dos recursos vinculados de impostos da União, inclusive daqueles que compõem o conceito de Manutenção e Desenvolvimento do Ensino - MDE; lutar contra os aumentos sistemáticos das contribuições sociais e econômicas não vinculadas à educação², exceto o salário educação, em favor da criação de impostos com destinação específica ao setor.

Em terceiro lugar, é importante considerar o tamanho do Estado e saber qual sua disposição para realizar políticas públicas, explicitando claramente os recursos destinados aos diferentes setores, assim como os segmentos da população priorizados.

Em quarto lugar é preciso jogar luz e controle social sobre o Sistema "S" que movimenta quase $\mathrm{R} \$ 12$ bilhões de recursos públicos sem qualquer visibilidade.

Finalmente, em quinto lugar, deve-se enfrentar a sangria da dívida pública que consome, no pagamento de juros e encargos, o dobro do que se gasta em educação no país.

Portanto, é imprescindível colocar a educação como prioridade nacional e reconhecer que esta área, para superar décadas de déficits e descuidos governamentais, necessita de consideráveis recursos financeiros bem aplicados.

\section{PERCEPÇÕES DE QUESTÕES DO FINANCIAMENTO NO PDE}

O contexto em que se descortina o PDE é marcado por um momento na política nacional em que se oferecem à nação grandes planos de Estado, que demarcam uma nova lógica governamental. Há um plano para cada setor

2. Cabe comentar que, muito embora a atual proposta de Reforma Tributária em discussão no Congresso Nacional sinalize para a transformação de algumas contribuições em impostos, o que seria positivo para o financiamento da educação, é importante se ter concretamente qual é a base de impostos sobre a qual incidirá a vinculação para a educação, pois há sempre o sério risco de uma redução dos recursos para o setor, basta se tomar como exemplo a existência da Desvinculação dos Recursos da União, que ainda retira 20\% dos recursos de impostos da União vinculados à educação. 
da ação do Estado, com características marcadamente econômicas, mas com destaque também para os aspectos sociais e o desenvolvimento ambiental e sustentável.

O mais famoso, e que de certa forma "inspira" os demais por sua exposição cotidiana na grande imprensa, é o Plano de Aceleração do Crescimento - PAC. Tal inspiração levou a que os diferentes arranjos estratégicos setoriais incluíssem a sigla em seu nome, como "PAC da Ciência e Tecnologia", "PAC da Saúde", "PAC da Cultura", e o próprio PDE passou a ser chamado de "PAC da Educação".

O processo de elaboração do PDE constitui ainda uma incógnita, mas há várias hipóteses a esse respeito. Uma delas é a de que houve uma "encomenda" ao MEC para realizar algo semelhante ao PAC e, como este é coordenado pela própria ministra Dilma Rousseff, o mesmo deveria ser coordenado pelo ministro da Educação. Outra é que nomes fortes no Partido dos Trabalhadores, com diferentes projetos para o MEC, disputavam o ministério no segundo mandato do presidente Lula (no primeiro mandato, Fernando Haddad foi antecedido por Cristovam Buarque e Tarso Genro) e que, por esta razão, o PDE seria uma medida "de contenção" inclusive com vistas a manter o ministro e seu staff em seus cargos.

Independentemente das razões de seu surgimento, o modo como se compôs o PDE e suas 40 ações (algumas versões iniciais apresentavam 27 ações) revela que foi elaborado às pressas. Observe-se, por exemplo, que várias dessas ações já faziam parte do programa de governo do primeiro mandato de Lula, como o Fundeb, enquanto outras que já estão sendo implementadas ficaram fora do plano, como o Programa Universidade para Todos - Prouni -, o Exame Nacional do Ensino Médio - Enem -, o Sistema Nacional de Avaliação da Educação Superior - Sinaes - e o Sistema Nacional de Avaliação da Educação Básica - Saeb -, entre outros.

A criação de um link para o PDE no Portal do MEC na internet, inicialmente apenas com a descrição das ações e depois com um material elaborado para a divulgação do plano, assim como a estratégia de sua apresentação nacional pelos principais quadros do MEC, incluído o ministro Haddad, via Caravana da Educação, mostram essa "construção do PDE em processo". Parece ignorarse a necessidade de elaboração dos atos normativos para regulamentar cada ação, o que requer prazos e procedimentos específicos, muitos dos quais dependentes de aprovação do legislativo. 
O documento que talvez traduza melhor as concepções, os posicionamentos e as intenções do MEC é "O Plano de Desenvolvimento da Educação: razões princípios e programas". Ele deixa claro que o plano deve se consolidar como política de Estado, visando o enlace entre educação e desenvolvimento econômico e social, como estrutura capaz de fazer frente ao problema da desigualdade de oportunidades:

A razão de ser do PDE está precisamente na necessidade de enfrentar estruturalmente a desigualdade de oportunidades educacionais. Reduzir desigualdades sociais e regionais, na educação, exige pensá-la no plano do País. O PDE pretende responder a esse desafio, através de um acoplamento entre as dimensões educacional e territorial operado pelo conceito de arranjo educativo. Não é possível perseguir a eqüidade sem promover esse enlace. [...] $\bigcirc$ enlace entre educação e desenvolvimento é essencial na medida em que é por meio dele que se visualizam e se constituem as interfaces entre a educação como um todo e as outras áreas de atuação do Estado. Não importa a abrangência do território considerado, o bairro ou o país. A relação recíproca entre educação e desenvolvimento só se fixa quando as ações do Estado são alinhadas e os nexos entre elas são fortalecidos, potencializando seus efeitos mútuos. [...] Desse movimento de busca de sintonia das políticas públicas entre si depende a potencialidade dos planos setoriais, inclusive o educacional, que passam, nesses termos, à condição de exigência do desenvolvimento econômico e social, garantindo-se que o todo seja maior que a soma das partes. (Brasil, 2007, p.6-7)

O documento mostra ainda que sua concepção sistêmica exige uma conexão entre etapas, níveis e modalidades da educação básica (inclusive a alfabetização) com a educação profissional e educação superior, de modo a potencializar as políticas para o setor e para que elas se reforcem mutuamente. Essa conexão seria estabelecida mediante o "regime de colaboração", descrito de forma muito ampla e genérica:

Os propósitos do PDE, dessa forma, tornam o regime de colaboração um imperativo inexorável. Regime de colaboração significa compartilhar competências políticas, técnicas e financeiras para a execução de programas de manutenção e 
desenvolvimento da educação, de forma a concertar a atuação dos entes federados sem ferir-lhes a autonomia. Essa simples divisão de tarefas, se articulada em grandes eixos (educação básica, superior, profissional e continuada), com regras transparentes e metas precisas, passíveis de acompanhamento público e controle social, pode pôr em marcha um avanço perceptível e sólido. (Brasil, 2007, p. |0-||)

Sobre o financiamento da educação, o documento diz que os

... repasses da União aos estados e municípios relativos ao salário-educação saltaram de $R \$ 3,7$ bilhões em 2002 para $R \$ 7$ bilhões em 2006 e que o investimento mínimo por aluno do ensino fundamental, ainda na vigência do Fundef, teve reajuste de $26 \%$ acima da inflação. A merenda escolar, que teve seu valor reajustado em $70 \%$ após uma década sem reajuste, foi estendida à creche, enquanto o programa do livro didático, pela primeira vez, atendeu aos estudantes do ensino médio. (Brasil, 2007, p. I8)

Esquece-se de dizer que dois terços dos recursos do salário-educação provêm das receitas dos estados e municípios e que o aumento real do valor mínimo por aluno do Fundef no governo Lula resultou da ampliação dessas receitas e da queda do número de matrículas. Não houve aporte da União, cuja participação continua muito abaixo do definido em lei. De resto, deve-se ter em mente que a proposta de reforma tributária do governo elaborada pelo Ministério da Fazenda prevê extinguir, entre outras contribuições, o salário educação, que representaria $R \$ 7$ bilhões a menos para a educação básica. Embora o ministro da Fazenda assegure que não haverá perda para educação, que esta terá recursos do tesouro, o risco é evidente.

Ainda sobre o financiamento, o documento destaca as vantagens do Fundeb em relação ao Fundef:

Fundeb, por sua vez, ao substituir o Fundef, trouxe pelo menos duas vantagens: I) aumentou substancialmente o compromisso da União com a educação básica, ampliando o aporte, a título de complementação, de cerca de $\mathrm{R} \$ 500$ milhões (média no Fundef) para cerca de $\mathrm{R} \$ 5$ bilhões de investimento ao ano; 
e 2) instituiu um único fundo para toda a educação básica, não apenas para o ensino fundamental. Trata-se, no que diz respeito à educação básica, de uma expressão da visão sistêmica da educação, ao financiar todas as suas etapas, da creche ao ensino médio, e ao reservar parcela importante dos recursos para a educação de jovens e adultos. É também a expressão de uma visão de ordenação do território e de desenvolvimento social e econômico, na medida em que a complementação da União é direcionada às regiões nas quais o investimento por aluno é inferior à média nacional. [...] Três inovações foram incorporadas ao Fundeb: I) a diferenciação dos coeficientes de remuneração das matrículas não se dá apenas por etapa e modalidade da educação básica, mas também pela extensão do turno: a escola de tempo integral recebe $25 \%$ a mais por aluno matriculado; 2) a creche conveniada foi contemplada para efeito de repartição dos recursos do Fundo; e 3) a atenção à educação infantil é complementada pelo Prolnfância, programa que financia a expansão da rede física de atendimento da educação infantil pública. (Brasil, 2007, p. I8)

Não se pode negar o avanço que o Fundeb representa em relação ao Fundef, no que se refere ao aumento da contribuição financeira da União, à melhoria do controle social e à recuperação do conceito de financiamento da educação básica como um todo. Contudo, não se pode esquecer que os recursos da União no novo fundo serão da ordem de apenas 10\% dos recursos aportados pelos estados e municípios ${ }^{3}$, enquanto a sua participação na carga tributária líquida é de cerca de 60\% do total.

Para concluir, em tom crítico, o texto alerta para a necessidade de ampliar os recursos para a educação, com base em um percentual do PIB, novamente ressaltando as ações e recursos previstos para o PDE, incluindo aí o Fundeb. E condena as matrizes de políticas educacionais pautadas em recompensas para os professores, de acordo com o desempenho dos alunos em exames e em metas preestabelecidas por Secretarias de Educação, como é o caso daquelas recentemente divulgadas no Estado de São Paulo. Diz o documento:

3. Embora a legislação fale em "no mínimo 10\%", sabemos que, na tradição orçamentária brasileira para a educação, o "mínimo" tende a transformar-se em "máximo". 
Estudiosos da educação, em especial economistas, têm defendido a tese de que o Brasil não precisa ampliar os investimentos em educação como proporção do Produto Interno Bruto. Alegam que o patamar atual, de 4\%, aproxima-se da média dos países desenvolvidos, o mesmo valendo para a relação entre o investimento na educação básica e o investimento na educação superior, de cerca de quatro para um. Esta abordagem, contudo, perde de vista dois aspectos: nosso baixo PIB per capita e nossa elevada dívida educacional. Se quisermos acelerar o passo e superar um século de atraso no prazo de uma geração, não há como fazê-lo sem investimentos na educação da ordem de 6\% a 7\% do PIB. Neste esforço, que deve ser nacional, o PDE, considerada a complementação da União ao FUNDEB, acrescenta, a partir do quarto ano de seu lançamento, $R \$ 19$ biIhões anuais ao orçamento do Ministério da Educação, ou 0,7\% do PIB, apenas como contrapartida federal. Outro equívoco comum é a defesa de um sistema de incentivos composto de prêmios e punições, em geral de caráter pecuniário, às escolas ou às redes educacionais que cumprirem ou não metas de qualidade, em geral preestabelecidas. Esta perspectiva desconsidera o fato de que restringir o financiamento de escolas ou sistemas educacionais por queda de desempenho pode significar punir uma segunda vez aquele que já não viu respeitado seu direito de aprender - o educando. O regime de colaboração deve prever o aumento das transferências automáticas de recursos às escolas e às redes educacionais que demonstrem capacidade de avançar com suas próprias forças e o aumento das transferências de recursos condicionado à elaboração e ao cumprimento de um plano de trabalho para as escolas e as redes educacionais que necessitem de apoio técnico e financeiro. Em outras palavras, deve-se equalizar as oportunidades educacionais pelo aumento do financiamento, diferenciando-se apenas o caráter do apoio, de modo a garantir a ampliação da esfera de autonomia das escolas e das redes educacionais. (Brasil, 2007, p.39-40)

Não deixa de ser curioso, contudo, o fato do PDE usar as variações no Ideb (Índice de Desenvolvimento da Educação Básica) como referência para o repasse de recursos às escolas públicas. Não estariam os formuladores do plano cometendo o mesmo erro que criticam? A outra questão em aberto é: onde estariam os citados $0,7 \%$ do PIB em recursos federais adicionais propiciados pelo PDE? 


\section{POSICIONAMENTOS SOBRE O FINANCIAMENTO NO PDE}

O grande problema na análise do financiamento do PDE refere-se à falta de dados sistematizados. Quando se procura saber exatamente em que consiste o "plano" no sítio oficial do MEC na internet, ou em documentos legais, não se encontra nada parecido com um plano de verdade ${ }^{4}$. $O$ que se tem é um link que abre para uma página onde consta uma definição absolutamente genérica, a qual, por sua vez, conecta-se a outra página em que são listadas "as ações do PDE". Com o tempo novos documentos e ações foram acrescidos, numa formulação claramente feita a posteriori.

A despeito das recentes tentativas do MEC de apresentá-lo como um todo orgânico, o PDE está diluído em uma longa série de Decretos, Portarias, Editais, Termos, Chamadas, Protocolos de Intenção, Resoluções, Projetos de Leis etc. Talvez o primeiro documento legal a ele relacionado seja o Decreto n. 6.094/2007, que dispõe sobre a implementação do "Plano de Metas Compromisso Todos pela Educação". Curiosamente neste documento não se faz nenhuma referência explícita ao PDE. Além disso, do ponto de vista do financiamento, o decreto prima pela desobrigação do governo federal.

Outro problema é que não existe nenhum quadro que sintetize o conjunto das ações apresentadas na página da internet. Por isso, nossa primeira tarefa ${ }^{5}$ foi construir uma tabela reunindo as informações esparsas para ter uma visão geral das ações, assim como vislumbrar o impacto financeiro de cada uma delas (Consultar tabela I em anexo).

Da análise da Tabela I, conclui-se rapidamente que não existe qualquer previsão minimamente fundamentada dos custos das quarenta ${ }^{6}$ ações propostas. Observa-se ainda que consta entre elas uma série de ações que anteriores ao PDE e que são apresentadas como frutos desse "plano", algumas das quais já vêm sendo implementadas há vários anos e outras que estão em discussão, como o Fundeb e o Piso Salarial Nacional dos Profissionais do Magistério.

4. É importante não confundir o PDE (Plano de Desenvolvimento da Educação) lançado em abril/2007 e que aqui se discute com o PDE (Plano de Desenvolvimento da Escola), programa iniciado no governo Fernando Henrique, com financiamento do Banco Mundial e que continua em vigor.

5. Este tópico baseou-se parcialmente em artigo publicado por um dos autores (Pinto, 2007).

6. Como já comentado, as 40 ações existentes quando da elaboração deste artigo já eram 53 em julho de 2008; não obstante a generalidade e a ausência de dados financeiros persistem. 
Espanta, também, do ponto de vista do financiamento, que se inclua no mesmo conjunto uma ação como o Concurso Literatura para Todos, com prêmios de $R \$ 10$ mil para nove autores de obras literárias destinadas a jovens e adultos em processo de alfabetização, e um programa do porte do Plano de Metas do PDE, que previa destinar, em 2007, R\$ I bilhão para cerca de 1.000 municípios com os menores valores de Ideb.

Aliás, a grande questão era saber de onde sairia este $R \$$ | bilhão que, de fato, do ponto de vista do financiamento, é o único dado novo do PDE, uma vez que tanto o Fundeb, como o Piso Salarial Nacional estão muito além e muito acima dele. Uma comparação entre as leis orçamentárias de 2006 e 2007 mostra que, no período, a Função Educação teve um acréscimo de $\mathrm{R} \$ 4,5$ bilhões. Contudo, somente para cobrir o aumento da contribuição da União para o Fundeb ( $+R \$ 1,6$ bilhão) e dos recursos para a expansão das instituições federais de educação superior e formação profissional e tecnológica ( $+\mathrm{R} \$ 2,4$ bilhões) foram consumidos $90 \%$ desse valor.

Restava a pergunta: de onde viriam os recursos para financiar o $R \$$ । bilhão do "plano de metas" e as demais ações propostas? O mais grave de tudo isso é que, ao se analisar a execução orçamentária do governo federal (que é onde se vê a prioridade real de uma determinada área) em despesas com MDE, constata-se que as despesas liquidadas em 2007 (R\$ I 5,7 bilhões) foram inferiores, em termos nominais, às de 2006 (R\$ 17, I bilhões). Se considerarmos os restos a pagar em MDE, as despesas de 2007 sobem para $R \$$ 17,6 bilhões, valor que, em termos reais, ainda é inferior ao de 2006 e ainda está muito aquém da previsão atualizada para 2007, de $R \$ 23,7$ bilhões. Portanto, não há o que comemorar.

Um dado positivo é que na Proposta de Lei Orçamentária - PLOA - de 2008 prevê-se um crescimento em termos nominais de $\mathrm{R} \$ 4,5$ bilhões para a função Educação (21\%) em relação à 2007. Descontando-se desse total o aumento da complementação da União ao Fundeb, de $\mathrm{R} \$$ | bilhão, resta ainda a expressiva quantia de $R \$ 3,5$ bilhões. Uma análise dos programas da PLOA-2008 indica que o aumento foi todo concentrado no programa Brasil Escolarizado, que incorporou recursos antes alocados para os programas Desenvolvimento do Ensino Fundamental, Desenvolvimento do Ensino Médio e Valorização e Formação de Professores e Trabalhadores da Educação Básica, todos extintos. Foi criado também um novo programa: Qualidade na Escola, 
com um orçamento de $\mathrm{R} \$ 668$ milhões. Um dado destoante é o pequeno aumento (3,5\% em termos nominais) dos recursos para o programa Brasil Universitário, que substitui o Universidade do século XXI, quando o PDE sinaliza grande expansão do ensino superior.

Entre as subfunções da PLOA-2008 constata-se que foi criado um grande "guarda-chuva" sob a rubrica Transferências para a Educação Básica, que sozinha absorverá $R \$ 4,7$ bilhões, ao que tudo indica, abrigando a complementação da União para o Fundeb ( $\mathrm{R} \$ 3$ bilhões que devem ser atualizados monetariamente) e boa parte das ações previstas no PDE. Contudo, ainda existe o risco de a educação ser afetada com os cortes orçamentários ainda em discussão no Congresso Nacional devido à perda de cerca de $\mathrm{R} \$ 40$ bilhões de receita que representou a extinção da Contribuição Provisória sobre Movimentação Financeira - CPMF. Por fim, um comentário sobre um dos pilares do PDE, a valorização dos profissionais da educação. Uma ação política como esta é de fundamental importância para a educação básica nacional, porém, é de se ressaltar a morosidade de tramitação no Congresso Nacional do Projeto de Lei de piso salarial do magistério público da educação básica (conceito que exclui os demais profissionais da educação), que deveria ter sido aprovado até 3 I/8/2007.

$O$ que se pode concluir é que o PDE foi lançado mais de olho no marketing político do que na viabilidade financeira. E, o que é pior, serve para escamotear a discussão sobre o cumprimento da meta do Plano Nacional de Educação - este sim um plano de verdade, aprovado pelo Congresso Nacional - e sobre a derrubada do veto aposto por Fernando Henrique Cardoso em 200 I à ampliação dos gastos públicos com a educação para 7\% do PIB.

\section{O PDE EM DEBATE}

Muitas das inquietações e dúvidas expostas aqui estiveram presentes e foram reiteradas - algumas até de forma acalorada - por ocasião do seminário itinerante realizado entre 15 e 18 de outubro de 2007, que contou, inclusive, com a participação do ministro da Educação, na abertura, e de representantes do MEC nas mesas-redondas.

De tudo o que lá se expôs e debateu, mesmo reconhecendo méritos em suas propostas, houve da parte dos debatedores e do público uma reiteração das críticas que já vinham sendo veiculadas pela imprensa e em pequenos cír- 
culos. Se do ponto de vista aritmético, as contas não fecham e não aparecem claramente explicitadas as fontes de onde emergirão os recursos, identificamse limites já na própria concepção do plano e na forma como foi divulgado. Falta sintonia entre a agenda meramente retórica e o estabelecimento das condições efetivas para que as ações propostas se tornem realidade. Além desse aspecto, foi muito questionado o fato de o PNE não ter sido levado em conta e, em contrapartida, se ter concedido um tratamento preferencial "à campanha organizada por setores do empresariado nacional", consolidada no movimento Todos pela Educação.

$\mathrm{Na}$ defesa que fizeram dos procedimentos adotados, os representantes do MEC utilizaram expressões que revelariam uma estratégia de concessão, sem perda do foco principal ("empresário também é cidadão", "eu sei de que lado estou" "fui militante" etc.) e argumentos de autoridade, como tentativa de dar uma legitimidade baseada em experiências realizadas noutros países, para algumas das ações questionadas pelos presentes ("estudos da OCDE apontam que..."; "na Finlândia...", "na Inglaterra..." etc.). Além do argumento, pronunciado sistematicamente, de que o PDE é uma proposta "em construção", está ainda "em debate", "aberta às contribuições"...

Outro aspecto crítico, também já mencionado, foi a percepção geral de que é impossível dissociar - e nem os representantes do MEC se esforçaram por fazê-lo - a sintonia, o momento e a agenda adotada para o lançamento do PDE do midiático lançamento do Plano de Aceleração do Crescimento PAC - e de seus múltiplos derivativos, num momento em que a titularidade do ministério era alvo de intenso ataque especulativo quanto à sua manutenção no grupo de ministros do novo mandato do governo Lula que se iniciava.

Contudo, nada suscitou mais questionamentos do que a adoção (no plano) e defesa (no Seminário) de mecanismos de avaliação centrados no desempenho dos alunos como forma de estimular a qualidade da educação e estabelecimento de condicionantes para o repasse de recursos aos governos subnacionais, mediante metas previamente acordadas.

Nesse sentido, não há como discordar de Araújo quando argumenta que

... ○ PDE mantém a lógica de que o papel da União é de estimular a produção da qualidade e isso será feito pela comparação, classificação e pela seleção. Esses elementos incorporam, conseqüentemente, como inerente aos seus resultados 
a exclusão, o que é incompatível com o direito de todos à educação. Premiar as escolas que atingirem determinadas metas via aumento de recursos do PDDE ${ }^{7}$ é bem sintomático da permanência da visão enunciada acima. (Araújo, 2007, p.8)

De fato, para além da manutenção das diretrizes básicas da política econômica iniciada no governo anterior, com reflexos negativos para o financiamento da educação, há outras identidades e semelhanças entre a política educacional daquele período e algumas das iniciativas sugeridas no PDE, sobretudo o "furor avaliatório" (que tem como expoentes o Ideb, a Prova Brasil e sua versão caçula, a Provinha Brasil), menos pelo que significam e mais pelo status adquirido no plano.

Como 2008 é ano de eleições municipais, surge agora um novo risco. $\bigcirc$ de que aportes significativos de recursos da União que, se incluídos no Fundeb poderiam ensejar outro padrão de atendimento, elevando significativamente a qualidade do conjunto dos sistemas de ensino, sejam gastos de forma focalizada, mais ao sabor das demandas paroquiais e partidárias, ou das, ainda, pouco confiáveis oscilações do Ideb. Aliás, a divulgação em 2008 dos resultados da variação do Ideb que mostram um desempenho acima do esperado por parte do conjunto dos municípios brasileiros é mais motivo de preocupação do que de comemoração. Analisando-se, por exemplo, os dados divulgados pelo MEC de I.236 municípios (e fica a pergunta: como estão os demais?) referentes às séries iniciais do ensino fundamental, constata-se que mais da metade (668 municípios) apresentou uma variação positiva do Ideb na comparação igual ou maior que 30\% entre 2005 e 2007; 287 (23\%) tiveram uma variação igual ou maior a 40\%; 167 (13,5\%) viram seu Ideb crescer $50 \%$ ou mais; 18 municípios tiveram o índice dobrado e 4 triplicados. Ora, qualquer pesquisador ou gestor educacional sabe que as redes de ensino não apresentam saltos desta natureza em prazo tão curto. Quando analisamos os municípios que apresentaram crescimento igual ou acima de 50\% constatamos que a variação decorreu principalmente da variação positiva na taxa de aprovação, um dos dois componentes do Ideb. Sabe-se que se pode alterar a taxa de aprovação simplesmente através de uma medida administrativa (introdução de promoção continuada, por exemplo) sem qualquer impacto real na qualidade do ensino

7. Programa Dinheiro Direto na Escola, do governo federal. 
oferecido. Os estudos na área mostram também que as notas dos alunos estão muito vinculadas ao nível socioeconômico das famílias e, portanto, não sofrem grandes variações em intervalo curto de tempo. Por isso também demandam investigação os 185 municípios que apresentaram uma variação, entre 2005 e 2007, igual ou superior a 20\% na nota média padronizada para as séries iniciais do ensino fundamental.

Aqui inclusive reside um dos maiores problemas do Ideb. Os dois indicadores que o compõem (taxa de promoção e nota na Prova Brasil) dependem principalmente de fatores pouco associados à melhoria da qualidade de ensino. Falta ao Ideb uma dimensão que leve em conta os insumos educacionais (qualificação dos professores, recursos colocados à disposição dos alunos etc.). Da maneira como o índice está montado, ao invés de investir em medidas de longo prazo que sabidamente melhoram a qualidade do ensino, os municípios, para não verem minguar o repasse de recursos do governo federal, tendem a adotar medidas cosméticas, ou mesmo a valer-se de fraude. A imprensa noticiou casos de escolas que diziam a determinados alunos, aqueles que tinham as maiores dificuldades, que não precisariam vir à escola no dia da Prova Brasil, por exemplo.

O outro grande problema do Ideb é que a sua lógica leva inevitavelmente ao estabelecimento de ranking entre municípios e entre escolas. Ao contrário do que acontece em outros países onde os resultados dos testes são ponderados levando-se em conta o perfil socioeconômico dos alunos e o tamanho das escolas (dois fatores com forte influência nos resultados) o MEC divulga simplesmente as notas sem esse cuidado mínimo.

A adoção de um modelo de avaliação pautado nestas características, como ressalta Sandra Zákia Sousa:

... tende a imprimir uma lógica e dinâmica organizacional nos sistemas de ensino, que se expressam no estímulo à competição entre as instituições educacionais e no interior delas, refletindo-se na forma de gestão e no currículo. Quanto ao currículo, destaca-se sua possível conformação aos testes de rendimento aplicados aos alunos, que tendem a ser vistos como os delimitadores do conhecimento que "tem valor", entendido o conhecimento como o conjunto de informações a serem assimiladas pelos alunos e passíveis de testagem. Quanto à gestão, a perspectiva é o fortalecimento dos mecanismos discriminatórios. (Sousa, 2003, p. | 87-188) 
Os primeiros efeitos do PDE parecem confirmar essas previsões, feitas em 2003 em relação às políticas de avaliação do governo que então se encerrava (FHC), cuja lógica, não obstante, foi intensificada no governo seguinte (Lula), ao criar testes padronizados nacionais censitários, divulgando os resultados por escola. Os efeitos desse processo são conhecidos: a fuga das escolas com menores notas dos professores mais experientes e qualificados e dos alunos cujos pais apresentam maior envolvimento e possuem mais recursos, reforçando a desigualdade do sistema educacional.

\section{INDICANDO POSSÍVEIS CAMINHOS PARA O PDE}

A título de finalização propositiva para o financiamento do PDE, levantamos dez sugestões: por que o governo federal não:

I. começa a implementar as metas do PNE, incluindo-as em seu Plano Pluri-anual e "cobrando" o mesmo de estados e municípios?

2. apresenta uma proposta de reforma tributária que realmente priorize a realização de políticas públicas, com significativa ampliação de recursos (e não para a realização do superávit primário), em especial os recursos da educação?

3. estabelece um valor aluno-ano da educação básica não pautado em quanto a União se dispõe a destinar à educação básica, mas na quantia necessária para se assegurar um padrão mínimo de qualidade, como forma de induzir governos supranacionais a aplicarem mais recursos em educação?

4. demonstra claramente a intenção da quebra do veto de Fernando Henrique Cardoso para destinar 7\% do PIB para as escolas públicas no Brasil, tal como apresenta no próprio PDE?

5. demonstra a intenção de estabelecer um só valor aluno-ano do Fundeb para o todo o país, impedindo o prosseguimento das desigualdades sociais e educacionais regionais (pelas quais um aluno do Piauí recebe a metade dos recursos recebidos por seu colega de São Paulo), fixando, ao menos como meta até 2015 , que todo aluno brasileiro, não importa onde resida, receberá o mesmo investimento educacional? 
6. disponibiliza gratuitamente aos municípios projetos de construção e de equipamentos de creches (com dimensões e ambientes para atendimento para 50, 100 e I 50 crianças) e pré-escolas (com dimensões e ambientes para atendimento para 100, 200 e 400 crianças), com vistas a induzir um desejável padrão de qualidade de atendimento para essas faixas etárias?

7. cria um programa para compras de brinquedos, materiais e livros para as creches e pré-escolas, nos moldes do Programa do Livro Didático, com vistas a induzir um desejável padrão de qualidade de atendimento para essas faixas etárias?

8. envia um projeto de lei, como emenda à atual Lei de Diretrizes e Bases da Educação, que estabeleça os princípios gerais de composição, atribuições e natureza dos conselhos de educação, em âmbito federal, estadual e municipal, em moldes semelhantes aos conselhos de saúde, concentrando nesses órgãos uma série de atribuições que hoje estão dispersas (Fundeb, Merenda Escolar etc.) e tornando-os mais transparentes e democráticos?

9. Por que não criar um sistema de avaliação da educação básica que seja mais do que um mero conjunto de indicadores e de notas, que envolva mecanismos de auto-avaliação e avaliação externa, garantindo a participação de docentes, funcionários, pais e alunos no processo? 10. Por que não enviar ao Congresso Nacional um projeto de lei que regule o regime de colaboração entre os entes da federação no que se refere ao atendimento educacional, assegurando que antes de escolas estaduais, municipais, ou federais, as escolas sejam essencialmente públicas e apresentem um padrão básico de qualidade?

\section{REFERÊNCIAS BIBLIOGRÁFICAS}

ARAÚJO, L. Os Fios condutores do PDE são antigos. Disponível em: http:// www.redefinanciamento.ufpr.br/araujo2.pdf. Acesso em: 18 set. 2007.

BRASIL. Ministério da Educação. Plano de Desenvolvimento da Educação - PDE. Brasilia, 2007. (Caderno de divulgação das Ações do PDE.) 
O Plano de Desenvolvimento da Educação: razões, princípios e programas PDE. Brasília, 2007. (Caderno de divulgação das razões, princípios e programas do PDE.) Plano Nacional de Educação - PNE. Brasília, 1997.

BRASIL. Presidência da República. Decreto n. 6.094, de 24 de abril de 2007: dispõe sobre a implementação do Plano de Metas Compromisso Todos pela Educação. Brasília, 2007.

ASSOCIAÇÃO DOS DOCENTES DA UNIVERSIDADE DE SÃO PAULO-S-SIND. GT Educação. Mais recursos para a educação! In: CONGRESSO DA ANDES-SN, 27. Goiânia, 14-20 jan. 2008. Caderno de Textos do... Brasília: Andes-SN, 2008.

FÓRUM NACIONAL EM DEFESA DA ESCOLA PÚBLICA. Plano Nacional de Educação: proposta da sociedade brasileira. Brasília: Fondep, 1997.

PINTO, J. M. R. O Financiamento das ações propostas. São Paulo: Ação Educativa, 2007. (Em questão, 4: O Plano de Desenvolvimento da Educação.)

SOUSA, S. M. Z. L. Possíveis impactos das políticas de avaliação no currículo escolar. Cadernos de Pesquisa, São Paulo, n. I 19, p. I75-190, jul. 2003.

Recebido em: março 2008

Aprovado para publicação em: maio 2008 


\section{ANEXO}

AS AÇÕES DO PDE, ATOS NORMATIVOS E RECURSOS DA UNIÃO

\begin{tabular}{|c|c|c|c|}
\hline Ação & $\begin{array}{c}\text { Objetivo } \\
\text { (site do PDE) }\end{array}$ & Atos Normativos & Valor previsto \\
\hline I. Fundeb & $\begin{array}{l}\text { Financiamento da } \\
\text { educação básica* }\end{array}$ & $\begin{array}{l}\text { EC/53 de 20/I2/2006; Lei I I.494/2007; } \\
\text { Portaria n. 48/2007; } \\
\text { Portaria Normativa 4/2007; Resolução } \\
\text { MEC I/2007; Decreto 6.90 I/2007 }\end{array}$ & $\begin{array}{l}\mathrm{R} \$ 2 \text { bi } \\
(2007) ; \\
\mathrm{R} \$ 3 \text { bi em } \\
2008 \\
\end{array}$ \\
\hline $\begin{array}{l}\text { 2. Provinha } \\
\text { Brasil }\end{array}$ & $\begin{array}{l}\text { Avaliar, via exame, as } \\
\text { crianças de } 8 \text { anos de } \\
\text { idade }\end{array}$ & Portaria Normativa I0/2007 & $\begin{array}{l}\text { Sem } \\
\text { estimativa }\end{array}$ \\
\hline $\begin{array}{l}\text { 3. Transporte } \\
\text { escolar }\end{array}$ & $\begin{array}{l}\text { Financiamento para } \\
\text { compra de veículos } \\
\text { escolares* }\end{array}$ & $\begin{array}{l}\text { Resolução 3/2007 FNDE; } \\
\text { Termo de intenção MEC e BNDES; } \\
\text { Resolução 3.453/2007 BNDES; } \\
\text { Isenta do ICMS operações de compra do } \\
\text { Programa Caminho da Escola/ MEC }\end{array}$ & $\begin{array}{l}\mathrm{R} \$ 300 \mathrm{mi}(3 \\
\text { anos) }\end{array}$ \\
\hline $\begin{array}{l}\text { 4. Plano de } \\
\text { metas do } \\
\text { PDE }\end{array}$ & $\begin{array}{l}\text { Auxílio a municípios com } \\
\text { baixo ldeb }\end{array}$ & $\begin{array}{l}\text { Decreto 6.094/2007; } \\
\text { Termo de Adesão ao Plano de Metas } \\
\text { "Compromisso todos pela Educação"; } \\
\text { Consulta ao Ideb }\end{array}$ & $\begin{array}{l}\text { R\$ I bi (2007) } \\
\text { estimativa }\end{array}$ \\
\hline $\begin{array}{l}\text { 5. Brasil } \\
\text { Alfabetizado }\end{array}$ & $\begin{array}{l}\text { Aumenta repasse e } \\
\text { prioriza atendimento/ } \\
\text { rede pública* }\end{array}$ & $\begin{array}{l}\text { Decreto 6.093/2007; } \\
\text { Resolução I3/2007 do FNDE; } \\
\text { Resolução I2/2007 do FNDE; } \\
\text { Resolução I 8/2007 - PNLA 2008; } \\
\text { Edital de convocação - PNLA 2008; } \\
\text { Portaria Normativa 9/2007 - PNLA. }\end{array}$ & $\begin{array}{l}\mathrm{R} \$ 315 \mathrm{mi} \\
(2007)\end{array}$ \\
\hline $\begin{array}{l}\text { 6. Luz para } \\
\text { todos }\end{array}$ & $\begin{array}{l}\text { Levar luz elétrica a todas } \\
\text { as escolas (início: 2009) }\end{array}$ & & $\begin{array}{l}\text { Sem } \\
\text { estimativa }\end{array}$ \\
\hline $\begin{array}{l}\text { 7. Piso do } \\
\text { magistério }\end{array}$ & $\begin{array}{l}\text { PL do gov. federal: fixa } \\
\text { em } R \$ 850,00(20 \text { । } 0)^{*}\end{array}$ & Projeto de Lei & (idem Fundeb) \\
\hline $\begin{array}{l}\text { 8. Formação de } \\
\text { Professores }\end{array}$ & $\begin{array}{l}\text { Via Universidade } \\
\text { Aberta do Brasil - UAB } \\
\text { (Educação a distância)* }\end{array}$ & $\begin{array}{l}\text { Decreto 5.800/2006; } \\
\text { Portaria I84/2007; } \\
\text { Edital de Seleção UAB I/2006 - Seed/ } \\
\text { MEC/2006/2007. } \\
\end{array}$ & $\begin{array}{l}\text { Sem } \\
\text { estimativa }\end{array}$ \\
\hline $\begin{array}{l}\text { 9. Educação } \\
\text { superior - } \\
\text { Reuni }\end{array}$ & $\begin{array}{l}\text { Duplicar as vagas nas } \\
\text { universidades federais. } \\
\text { Em outro ponto fala em } \\
\text { duplicar as matrículas, } \\
\text { o que é diferente (I } 0 \\
\text { anos) }\end{array}$ & Decreto 6.096/2007 - Reuni & $\begin{array}{l}+20 \% \text { do } \\
\text { orçamento } \\
\text { das lfes }\end{array}$ \\
\hline
\end{tabular}




\begin{tabular}{|c|c|c|c|}
\hline Ação & $\begin{array}{c}\text { Objetivo } \\
\text { (site do PDE) }\end{array}$ & Atos Normativos & Valor previsto \\
\hline $\begin{array}{l}\text { 10. Acesso } \\
\text { facilitado }\end{array}$ & $\begin{array}{l}\text { Fies: aumenta o limite } \\
\text { financiado ( } 100 \%) \text {, a } \\
\text { carência e o prazo para } \\
\text { pagar* }\end{array}$ & Projeto de Lei que altera a Lei 10.260/200 I & $\begin{array}{l}\text { Sem } \\
\text { estimativa }\end{array}$ \\
\hline $\begin{array}{l}\text { I I. Biblioteca } \\
\text { na escola }\end{array}$ & $\begin{array}{l}\text { Obras literárias para } \\
\text { alunos do ensino médio } \\
\text { (atingir } 7 \text { milhões de } \\
\text { alunos) }\end{array}$ & $\begin{array}{l}\text { Resolução 2/2007 - FNDE- PNLD; } \\
\text { Resolução 4/2007 - FNDE - PNBE; } \\
\text { Resolução 5/2007 - FNDE - PNBEM; } \\
\text { Resolução I 8/2007 - FNDE- PNLA; } \\
\text { Edital de Convocação - Livros didáticos - } \\
\text { PNLA 2008; } \\
\text { Edital de Convocação - Obras de literatura } \\
\text { - PNBE 2008; } \\
\text { Portaria Normativa 9/2007 }\end{array}$ & $\begin{array}{l}\mathrm{R} \$ \mid 5,5 \\
\text { milhões } \\
(2008)\end{array}$ \\
\hline $\begin{array}{l}\text { 12. Educação } \\
\text { profissional }\end{array}$ & $\begin{array}{l}\text { Sair de } 700 \text { mil para } 2 \\
\text { milhões de alunos (4 } \\
\text { anos) a partir de } 2008\end{array}$ & $\begin{array}{l}\text { Decreto 6.095/2007 - Ifet; } \\
\text { Projeto de Lei; } \\
\text { Edital de Seleção I/2007/Seed/Setec/ } \\
\text { MEC - Projetos de EP a distância }\end{array}$ & $\begin{array}{l}\text { Sem } \\
\text { estimativa }\end{array}$ \\
\hline 13. Estágio & \begin{tabular}{|l|}
$\begin{array}{l}\text { Projeto de Lei estabelece } \\
\text { novas normas (jornada, } \\
\text { supervisão, duração) }\end{array}$ \\
\end{tabular} & Projeto de Lei 9.93/2004 & $\begin{array}{l}\text { Sem custo } \\
\text { previsto }\end{array}$ \\
\hline $\begin{array}{l}14 . \\
\text { Proinfância }\end{array}$ & $\begin{array}{l}\text { Recursos para a } \\
\text { construção de creches } \\
\text { e pré-escolas ( } 400 \\
\text { projetos/ano) }\end{array}$ & Resolução 6/2007 - FNDE Proinfância & $\begin{array}{l}\mathrm{R} \$ 800 \mathrm{mi}(4 \\
\text { anos })\end{array}$ \\
\hline \begin{tabular}{|l|} 
15. Salas \\
multifuncionais
\end{tabular} & $\begin{array}{l}\text { Equipamentos para } \\
\text { educação especial* } \\
\text { e capacitação de } \\
\text { professores. }\end{array}$ & $\begin{array}{l}\text { Portaria Normativa I2/2007; } \\
\text { Portaria Normativa I3/2007; } \\
\text { Edital I/2007 SEE/MEC - Salas de Recursos } \\
\text { Multifuncionais; } \\
\text { Edital 2/2007 SEE/MEC - Formação } \\
\text { Continuada de Professores de EE; } \\
\text { Edital 3/2007 MEC - Programa Incluir: } \\
\text { Acessibilidade na Educação Superior }\end{array}$ & $\begin{array}{l}\text { Sem } \\
\text { estimativa }\end{array}$ \\
\hline $\begin{array}{l}\text { 16. Pós- } \\
\text { doutorado } \\
\end{array}$ & $\begin{array}{l}\begin{array}{l}\text { Bolsas para recém- } \\
\text { doutores }(1.500)\end{array} \\
\end{array}$ & Portaria Interministerial 20/2007 - PNPD & $\begin{array}{l}\mathrm{R} \$ 77,4 \mathrm{mi} \\
\text { (est.) } \\
\end{array}$ \\
\hline $\begin{array}{l}\text { 17. Censo } \\
\text { pela internet }\end{array}$ & $\begin{array}{l}\text { Educacenso: censo } \\
\text { identifica o aluno* }\end{array}$ & $\begin{array}{l}\text { Portaria MEC 46/2007 - Instrui as etapas } \\
\text { do Censo } 2007\end{array}$ & $\begin{array}{l}\text { Sem } \\
\text { estimativa }\end{array}$ \\
\hline $\begin{array}{l}\text { 18. Saúde nas } \\
\text { escolas }\end{array}$ & $\begin{array}{l}\text { Atender via PSF (Saúde } \\
\text { da Família) alunos e } \\
\text { professores na escola } \\
\end{array}$ & $\begin{array}{l}\text { Portaria Interministerial I6/2007 - cria GT } \\
\text { para a elaboração de documento }\end{array}$ & $\begin{array}{l}\text { Sem } \\
\text { estimativa }\end{array}$ \\
\hline $\begin{array}{l}\text { 19. Olhar } \\
\text { Brasil }\end{array}$ & $\begin{array}{l}\text { Identificar crianças com } \\
\text { dificuldade visual e } \\
\text { fornecer óculos }\end{array}$ & $\begin{array}{l}\text { Portaria Interministerial I 5/2007 - institui o } \\
\text { Projeto Olhar Brasil. }\end{array}$ & $\begin{array}{l}\text { Sem } \\
\text { estimativa }\end{array}$ \\
\hline
\end{tabular}




\begin{tabular}{|c|c|c|c|}
\hline Ação & $\begin{array}{c}\text { Objetivo } \\
\text { (site do PDE) }\end{array}$ & Atos Normativos & Valor previsto \\
\hline $\begin{array}{l}\text { 20. Mais } \\
\text { educação }\end{array}$ & $\begin{array}{l}\text { Ampliar a jornada } \\
\text { escolar e os espaços } \\
\text { educativos }\end{array}$ & $\begin{array}{l}\text { Portaria Interministerial I7/2007 - institui o } \\
\text { Programa Mais Educação; } \\
\text { Portaria Normativa Interministerial 19/2007 } \\
\text { - Diretrizes para a cooperação entre MEC } \\
\text { e Ministério dos Esportes }\end{array}$ & $\begin{array}{l}\text { Não consta } \\
\text { repasse }\end{array}$ \\
\hline $\begin{array}{l}\text { 21. Educação } \\
\text { especial }\end{array}$ & \begin{tabular}{|l|} 
Identificar e monitorar \\
acesso e permanência \\
dos beneficiários do BPC \\
(benefício para idosos, \\
deficientes e incapacitados \\
para o trabalho) \\
\end{tabular} & $\begin{array}{l}\text { Portaria Normativa Interministerial I8/2007 } \\
\text { MEC e MPS para criação de Programa de } \\
\text { Acompanhamento do BCP/Loas }\end{array}$ & $\begin{array}{l}\text { Sem } \\
\text { estimativa }\end{array}$ \\
\hline $\begin{array}{l}\text { 22. Professor } \\
\text { equivalente }\end{array}$ & $\begin{array}{l}\text { Facilitar a contratação de } \\
\text { docentes nas federais }\end{array}$ & $\begin{array}{l}\text { Portaria Normativa Interministerial 22/2007 } \\
\text { MEC e MPOG - criação de banco de vagas } \\
\text { docentes }\end{array}$ & $\begin{array}{l}\text { Não implica } \\
\mathrm{R} \$\end{array}$ \\
\hline $\begin{array}{l}\text { 23. Guia de } \\
\text { tecnologias }\end{array}$ & $\begin{array}{l}\text { Divulgar boas } \\
\text { experiências em } \\
\text { tecnologia educacional } \\
\text { para educação básica } \\
\end{array}$ & $\begin{array}{l}\text { Edital de pré-qualificação de materiais e } \\
\text { tecnologias que promovam a qualidade da } \\
\text { educação básica }\end{array}$ & $\begin{array}{l}\text { Sem } \\
\text { estimativa }\end{array}$ \\
\hline $\begin{array}{l}\text { 24. Coleção } \\
\text { Educadores }\end{array}$ & $\begin{array}{l}\text { Enviar às escolas obras } \\
\text { de grandes educadores } \\
\text { (30: Brasil e 30: exterior) }\end{array}$ & $\begin{array}{l}\text { Termo de Autorização ao FNDE para } \\
\text { descentralizar recursos para a Fundação } \\
\text { Joaquim Nabuco para a execução da } \\
\text { Coleção Educadores }\end{array}$ & $\mathrm{R} \$ \mathrm{I}, \mathrm{I} \mathrm{mi}$ \\
\hline $\begin{array}{l}\text { 25. Dinheiro } \\
\text { na escola }\end{array}$ & $\begin{array}{l}\text { Adicional de } 50 \% \text { no } \\
\text { repasse do PDDE p/ } \\
\text { escolas que cumprirem } \\
\text { meta Ideb* }\end{array}$ & Resolução 9/2007 do FNDE - PDDE & $\begin{array}{l}\text { Sem } \\
\text { estimativa }\end{array}$ \\
\hline $\begin{array}{l}\text { 26. Concurso } \\
\text { público }\end{array}$ & $\begin{array}{l}\text { Ampliação de quadros } \\
\text { do FNDE e da rede } \\
\text { profissional* }\end{array}$ & $\begin{array}{l}\text { Portaria I22/2007 - FNDE/MEC - 191 } \\
\text { cargos para técnicos do FNDE; } \\
\text { Portaria I 23/2007 - MEC 2 } 100 \text { cargos } \\
\text { para lfets }\end{array}$ & $\begin{array}{l}\text { Sem } \\
\text { estimativa }\end{array}$ \\
\hline $\begin{array}{l}27 . \\
\text { Acessibilidade }\end{array}$ & $\begin{array}{l}\text { Eliminar barreiras } \\
\text { pedagógicas, } \\
\text { arquitetônicas e de } \\
\text { comunicação (Ifes) } \\
\end{array}$ & $\begin{array}{l}\text { Portaria Normativa I4/2007 - Programa } \\
\text { Incluir nas Ifes; } \\
\text { Edital 3/2007 Sesu/MEC - Programa } \\
\text { Acessibilidade na Educação Superior }\end{array}$ & $\begin{array}{l}\mathrm{R} \$ 2 \mathrm{mi} / 4 \\
\text { anos }\end{array}$ \\
\hline $\begin{array}{l}\text { 28. Cidades- } \\
\text { pólo }\end{array}$ & $\begin{array}{l}\text { Implantar I } 50 \text { novas } \\
\text { escolas técnicas federais } \\
(4 \text { anos)* }\end{array}$ & $\begin{array}{l}\text { Edital MEC - } 2007 \text { Chamada Pública: } \\
\text { acolhe propostas para instalação de I } 50 \\
\text { Ifets e escolas federais }\end{array}$ & $\begin{array}{l}\mathrm{R} \$ 500 \mathrm{mi} / \\
\text { ano }\end{array}$ \\
\hline $\begin{array}{l}\text { 29. Inclusão } \\
\text { digital }\end{array}$ & \begin{tabular}{|l|} 
Assegurar computadores \\
a todas as escolas \\
públicas (até 20 I 0)*
\end{tabular} & Ato de Autorização MEC - Proinfo-Rural & $\begin{array}{l}\mathrm{R} \$ 650 \mathrm{mi} / 4 \\
\text { anos }\end{array}$ \\
\hline $\begin{array}{l}\text { 30. Gosto } \\
\text { de ler }\end{array}$ & $\begin{array}{l}\text { Realizar a Olimpíada } \\
\text { Brasileira da Língua } \\
\text { Portuguesa (com Itaú } \\
\text { Social) } \\
\end{array}$ & $\begin{array}{l}\text { Protocolo de Intenções com Fundação Itaú } \\
\text { Cultural para promover a Olimpíada }\end{array}$ & $\begin{array}{l}\text { Sem } \\
\text { estimativa }\end{array}$ \\
\hline
\end{tabular}




\begin{tabular}{|c|c|c|c|}
\hline Ação & $\begin{array}{c}\text { Objetivo } \\
\text { (site do PDE) }\end{array}$ & Atos Normativos & Valor previsto \\
\hline $\begin{array}{l}\text { 31. Conteúdos } \\
\text { educacionais }\end{array}$ & \begin{tabular}{|l|} 
Apoiar financeiramente a \\
produção de conteúdos \\
educacionais digitais
\end{tabular} & $\begin{array}{l}\text { Edital de Seleção 0 I/2007 - Chamada } \\
\text { pública para apoio financeiro à produção de } \\
\text { conteúdos educacionais digitais multimídia }\end{array}$ & $\mathrm{R} \$ 75 \mathrm{mi}$ \\
\hline $\begin{array}{l}\text { 32. Livre do } \\
\text { analfabetismo }\end{array}$ & $\begin{array}{l}\text { Certificar município } \\
\text { (via selo) com } 96 \% \text { de } \\
\text { alfabetizados ou ldeb } \\
\text { elevado }\end{array}$ & $\begin{array}{l}\text { MEC oferecerá selos e certificados a } \\
\text { municípios e estados que aumentarem Ideb } \\
\text { e atingirem mais de } 96 \% \text { de alfabetização } \\
\text { de suas redes }\end{array}$ & $\begin{array}{l}\text { Não implica } \\
\mathrm{R} \$\end{array}$ \\
\hline $\begin{array}{l}\text { 33. Planos } \\
\text { escolares }\end{array}$ & $\begin{array}{l}\text { Capacitar e orientar a } \\
\text { elaboração de planos } \\
\text { escolares* }\end{array}$ & $\begin{array}{l}\text { MEC e FNDE - Proposição de cursos de } \\
\text { capacitação para secretarias municipais e } \\
\text { estaduais de educação }\end{array}$ & $\begin{array}{l}\text { Sem } \\
\text { estimativa }\end{array}$ \\
\hline $\begin{array}{l}\text { 34. Formação } \\
\text { na saúde }\end{array}$ & $\begin{array}{l}\text { Melhorar a formação de } \\
\text { profissionais da saúde }\end{array}$ & $\begin{array}{l}\text { Criação de Comissão Interministerial MEC } \\
\text { e Ministério da Saúde (PET- Saúde) }\end{array}$ & $\begin{array}{l}\text { Sem } \\
\text { estimativa }\end{array}$ \\
\hline $\begin{array}{l}\text { 35. Literatura } \\
\text { para Todos }\end{array}$ & $\begin{array}{l}\text { Premiar via concurso } \\
\text { obras literárias para } \\
\text { jovens e adultos em } \\
\text { alfabetização* }\end{array}$ & Edital MEC Concurso Literatura para Todos & $\begin{array}{l}\mathrm{R} \$ 90 \text { mil } \\
\text { (prêmios) }\end{array}$ \\
\hline $\begin{array}{l}\text { 36. Extensão, } \\
\text { ensino e } \\
\text { pesquisa }\end{array}$ & $\begin{array}{l}\text { Financiar projetos de } \\
\text { extensão em lfes, Cefets } \\
\text { e Inst. Estaduais de E. } \\
\text { Sup.* }\end{array}$ & $\begin{array}{l}\text { Programa de Apoio à Extensão Universitária } \\
\text { (Proext), criado em } 2003 \text { e está na } 5^{a} \text {. } \\
\text { edição. }\end{array}$ & $\mathrm{R} \$ 6 \mathrm{mi}$ \\
\hline $\begin{array}{l}37 . \\
\text { Licenciatura } \\
\text { de qualidade } \\
\end{array}$ & $\begin{array}{l}\text { Melhorar os cursos de } \\
\text { licenciatura* }\end{array}$ & $\begin{array}{l}\text { Programa de Consolidação das } \\
\text { Licenciaturas (Prodocência), criado em } \\
2006 .\end{array}$ & $\begin{array}{l}\mathrm{R} \$ 3 \mathrm{mi} \mathrm{m} \\
2007\end{array}$ \\
\hline $\begin{array}{l}\text { 38. Nova } \\
\text { Capes }\end{array}$ & $\begin{array}{l}\text { Projeto de lei (não } \\
\text { aprovado) amplia } \\
\text { quadro e atribuições da } \\
\text { Capes que passa apoiar } \\
\text { formação de professores } \\
\text { da educação básica } \\
\end{array}$ & Projeto de Lei 7.569/06, de junho de 2007 & $\begin{array}{l}\text { Sem } \\
\text { estimativa }\end{array}$ \\
\hline $\begin{array}{l}\text { 39. Incentivo } \\
\text { à Pesquisa }\end{array}$ & $\begin{array}{l}\text { Prevê redução fiscal para } \\
\text { empresas que investirem } \\
\text { em projetos de inovação } \\
\text { científica e tecnológica } \\
\text { desenvolvidos por } \\
\text { institutos públicos }\end{array}$ & Lei II.487 de 15/6/2007 & $\begin{array}{l}\text { Sem } \\
\text { estimativa }\end{array}$ \\
\hline $\begin{array}{l}\text { 40. Iniciação à } \\
\text { docência }\end{array}$ & \begin{tabular}{|l|} 
Incentivar (mediante \\
bolsas) a aproximação e \\
ingresso do licenciando \\
na docência da educação \\
básica ( 20 mil bolsas de \\
$\mathrm{R} \$ 300$, em 2008)
\end{tabular} & $\begin{array}{l}\text { Programa de Bolsa Institucional de Iniciação } \\
\text { à Docência - Pibid }\end{array}$ & $\begin{array}{l}\mathrm{R} \$ 75 \mathrm{mi} \\
(2008)\end{array}$ \\
\hline
\end{tabular}

* Programas já existentes embora possam ter sofrido modificações.

Fonte: www.mec.gov.br 